\title{
Potential fluid biomarkers for pathological brain changes in Alzheimer's disease: Implication for the screening of cognitive frailty
}

\author{
QINGWEI RUAN $^{1 *}$, GRAZIA D'ONOFRIO $^{2 *}$, DANIELE SANCARLO $^{2}$, ANTONIO GRECO $^{2}$ and ZHUOWEI YU ${ }^{1}$ \\ ${ }^{1}$ Shanghai Institute of Geriatrics and Gerontology, Shanghai Key Laboratory of Clinical Geriatrics, \\ Department of Geriatrics, Huadong Hospital, and Research Center of Aging and Medicine, Shanghai Medical College, \\ Fudan University, Shanghai 200040, P.R. China; ${ }^{2}$ Geriatric Unit \& Laboratory of Gerontology and Geriatrics, \\ Department of Medical Sciences, IRCCS 'Casa Sollievo della Sofferenza', San Giovanni Rotondo, I-71013 Foggia, Italy
}

Received February 22, 2016; Accepted July 18, 2016

DOI: $10.3892 / \mathrm{mmr} .2016 .5618$

\begin{abstract}
Cognitive frailty (CF) overlaps with early neuropathological alterations associated with aging-related major neurocognitive disorders, including Alzheimer's disease (AD). Fluid biomarkers for these pathological brain alterations allow for early diagnosis in the preclinical stages of $\mathrm{AD}$, and for objective prognostic assessments in clinical intervention trials. These biomarkers may also be helpful in the screening of CF. The present study reviewed the literature and identified systematic reviews of cohort studies and other authoritative reports. The selection criteria for potentially suitable fluid biomarkers included: i) Frequent use in studies of fluid-derived markers and ii) evidence of novel measurement techniques for fluid-derived markers. The present study focused on studies that assessed these biomarkers in $\mathrm{AD}$, mild cognitive impairment and non-AD demented subjects. At present, widely used fluid biomarkers include cerebrospinal fluid (CSF), total tau, phosphorylated tau and amyloid- $\beta$ levels. With the development of novel measurement techniques and improvements in understanding regarding the mechanisms underlying aging-related major neurocognitive disorders, numerous novel biomarkers associated with various aspects of AD neuropathology are being explored. These include specific measurements of $A \beta$ oligomer or monomer forms, tau proteins in the peripheral
\end{abstract}

Correspondence to: Dr Zhuowei Yu, Shanghai Institute of Geriatrics and Gerontology, Shanghai Key Laboratory of Clinical Geriatrics, Department of Geriatrics, Huadong Hospital, and Research Center of Aging and Medicine, Shanghai Medical College, Fudan University, 221 West Yan An Road, Shanghai 200040, P.R. China

E-mail: hdyuzhuowei@163.com

${ }^{*}$ Contributed equally

Key words: Alzheimer's disease, mild cognitive impairment, preclinical $\mathrm{AD}$, cognitive frailty, fluid-derived markers plasma and CSF, and novel markers of synaptic dysfunction, neuronal damage and apoptosis, neuronal activity alteration, neuroinflammation, blood brain barrier dysfunction, oxidative stress, metabolites, mitochondrial function and aberrant lipid metabolism. The proposed panels of fluid biomarkers may be useful in the early diagnosis of $\mathrm{AD}$, prediction of the progression of AD from preclinical stages to the dementia stage, and the differentiation of AD from non-AD dementia. In combination with physical frailty, the present study surmised that these biomarkers may also be used as biomarkers for $\mathrm{CF}$, thus contribute to discovering causes and informing interventions for cognitive impairment in individuals with $\mathrm{CF}$.

\section{Introduction}

Cognitive frailty $(\mathrm{CF})$ refers to a heterogeneous clinical syndrome found in elderly individuals that excludes those with AD and other types of dementia, and is characterized by concurrent physical frailty and potentially reversible cognitive impairment (1). CF includes reversible and potentially reversible subtypes (2), and may represent a precursor to neurodegenerative processes. Although studies regarding CF biomarkers are scarce, the neuropathological processes overlap with those in individuals with $\mathrm{AD}$ and/or other neurodegenerative diseases, and the final outcomes of $\mathrm{CF}$ are AD or non-AD dementia. Therefore, excluding biomarkers of physical frailty, other biomarkers, such as amyloid- $\beta$ (A $\beta)$ accumulation, neurodegeneration or neuronal injury, may be considered biomarkers for CF. Reversible CF occurs in the later stages of preclinical $\mathrm{AD}$ or at the pre-mild cognitive impairment (MCI) stage due to other causes, and can be diagnosed based on subjective cognitive decline (SCD) and/or positive biomarkers. Cognitive impairment in potentially reversible $\mathrm{CF}$ is comparable to $\mathrm{MCI}$.

Diagnosis of preclinical sporadic AD or other suspected non-Alzheimer pathologies in reversible CF depends on the evidence of pathophysiological alterations in the brain, as demonstrated by established fluid and imaging biomarkers. Neuronal injury or neurodegeneration-associated biomarkers offer chances to predict cognitive impairment progression and prognosis, and to evaluate outcomes of disease-modifying 
interventions in clinical trials (3). However, there are several challenges, including invasive or expensive detection techniques, and time-consuming detection procedures for the measurement of current biomarkers for disease-induced early neuropathological alterations. The most important challenges associated with current biomarkers are the measurement techniques; for example, current standard enzyme-linked immunosorbent assay (ELISA) methods are insensitive to very low concentrations of biomarkers in cerebrospinal fluid (CSF) and blood (4). Therefore, blood- and urine-based biomarkers may be more attractive biomarkers for the screening of neuropathological alterations in $\mathrm{AD}$ and $\mathrm{CF}$. The present study systematically reviewed the advance of fluid biomarkers for the pathological process of $\mathrm{AD}$, which will likely aid in the discovery of biomarkers for CF.

\section{Materials and methods}

Literature search. The search strategy was updated according to best practice recommendations $(5,6)$. Literature searches were performed using MEDLINE (between 1996 and April 2015; https://www.nlm.nih.gov/bsd/pmresources.html) and PubMed (between 1990 and November 2015; www.ncbi. nlm.nih.gov/pubmed) databases. The search queries included: i) Blood, ii) cerebrospinal fluid, iii) urine, iv) Alzheimer's disease and v) mild cognitive impairment.

Study selection. A reviewer scrutinized abstracts found by electronic search in order to identify articles meriting a full review. Entire articles were reviewed before data were extracted from pertinent papers.

The inclusion criteria used for the review protocol were as follows: i) Age $\geq 60$ years, ii) diagnosis of AD according to the criteria of the National Institute on Aging-Alzheimer's Association (NIAAA) (7) or diagnosis of MCI according to NIAAA criteria (8) with a confirmed progression to AD assessed by clinical follow-up, and iii) suitable clinical assessments of cognitive and functional impairment, quality of life and clinical evaluations. The exclusion criteria were: i) No English editing (as we lacked resources for translation), ii) diagnosis of non-AD dementia, and iii) MCI that did not progress to AD. No limits were defined on the grounds of disease duration or drug treatment.

Data extraction. A total of 2,243 papers, and 92 additional articles from recent reviews were found. After reviewing the abstracts, 648 papers were obtained on the basis of the aforementioned inclusion/exclusion criteria and duplicates. After screening, 259 papers were reserved, of which 36 reviews and 158 full-text articles were excluded after more in-depth examination, on the basis of the same inclusion/exclusion criteria. Therefore, 65 published studies were considered eligible for the current review (Fig. 1). Data extraction was divided into four categories among the authors by expertise: Potential blood-derived markers of $\mathrm{AD}$ and $\mathrm{MCI}$, potential CSF-derived markers of $\mathrm{AD}$ and $\mathrm{MCI}$, potential urinary-derived markers of AD and MCI, and cell-based techniques for analyzing tau pathogenicity. Co-authors provided a detailed abstract of all studies describing their strengths and weaknesses, as well as a general evaluation of the category $(9,10)$. The quality of studies was assessed using the Standards for the Reporting of Diagnostic Accuracy Studies in dementia (11).

\section{Results and Discussion}

Potential blood-derived markers of AD and MCI. The potential blood-derived biomarkers for $\mathrm{AD}$ and $\mathrm{MCI}$ are presented in Table I. The ratio of amyloid precursor protein (APP) forms contained in the platelets was significantly decreased in individuals with mild AD, very mild AD and MCI (12), individuals with MCI that progressed to AD dementia (13), and patients with AD that exhibited cognitive decline (14). Compared with patients with non-amnestic MCI, patients with amnestic MCI exhibited increased levels of coated-platelets, which are produced by collagen and thrombin activation. In addition, the increases in coated-platelet levels were associated with an increased risk for the progression to AD (15). There were significantly lower levels of $A \beta 1-42$ and $A \beta 1-42 / 1-40$ in the plasma of patients with AD compared with patients with non-AD dementia, or in patients with AD-type MCI compared with patients with other types of MCI (16). A cross-sectional study demonstrated that plasma A $\beta 1-40$ levels were independently associated with microvascular brain injury (17). However, plasma A $\beta$ peptide levels only weakly predicted the conversion to AD in normal individuals (18). In addition, plasma $A \beta$ monomer biomarkers were not sensitive enough to discriminate patients with AD-type MCI from patients with early $\mathrm{AD}$, or to distinguish patients with other types of $\mathrm{MCI}$ from patients with other types of early dementia.

Tau proteins in the serum are potential biomarkers for neuronal degeneration or damage. A novel ultrasensitive digital immunoassay technology, which is referred to as a single-molecule ELISA, is able to detect clinically relevant proteins in the serum at concentrations $<10^{-15} \mathrm{M}$ (19). Compared with the classic ELISA, this ultrasensitive technique is 1,000-fold more sensitive. The lower limit of quantification is $0.02 \mathrm{pg} / \mathrm{ml}$, which is 100 times higher than the plasma levels of tau proteins $(\sim 5 \mathrm{pg} / \mathrm{ml})$. This ultrasensitive technique has detected dynamic changes in tau protein in the serum after hypoxic brain injury, and a mean 2-fold increase in AD individuals, however with some overlaps with the levels in patients with MCI and the controls (20). However, rare protein isoforms that result due to cleavage of the tau protein and disease-specific tau phosphorylation are not recognized by currently available assays (21).

Aberrant lipid metabolism is associated with the pathophysiological processes in AD. Some plasma phospholipids may therefore be considered biomarkers for AD. Reductions in the levels of these phospholipids may accurately predict the progression of an individual from normal cognition to MCI or AD within 2 years $(22,23)$. A biomarker panel that detected decreases in the levels of 10 phospholipids in blood plasma that reflect cell membrane integrity may be able to predict which cognitively normal elderly adults will develop MCI and AD with $>90 \%$ accuracy (22). Early studies have reported that phosphatidylcholine molecules in AD brains are decreased and that their main metabolite, glycerophosphocholine, is increased $(23,24)$. However, some phosphatidylcholines produced by the sequential methylation of another phosphatide, such as phosphatidylethanolamine, were increased in 


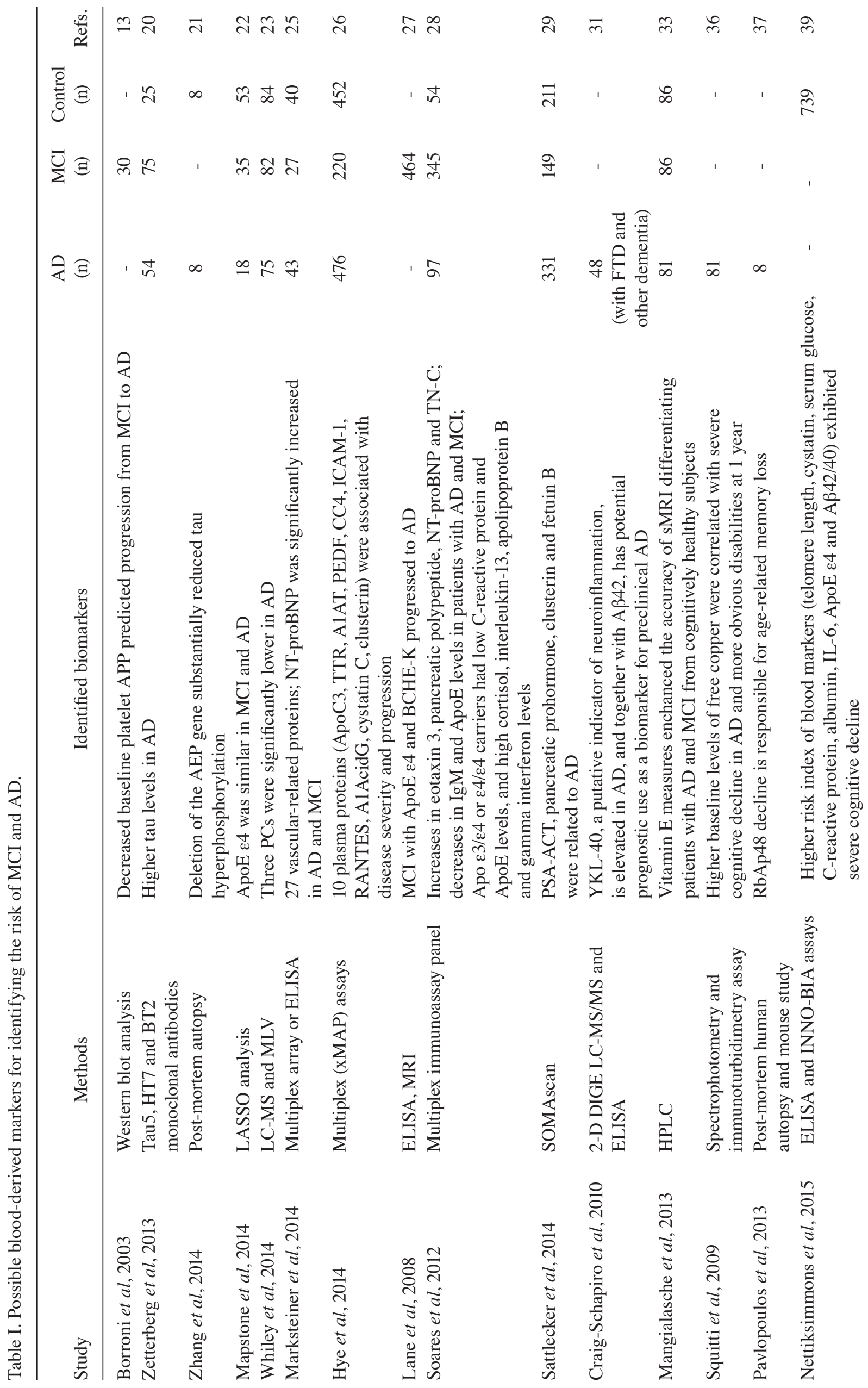


AD brains. It has previously been demonstrated that three phosphatidylcholine molecules were significantly diminished in patients with $\mathrm{AD}$ compared with patients with $\mathrm{MCI}$ or age-matched individuals (23).

A previous study measured the plasma levels of 27 vascular-related proteins using multiplex assays or ELISA in patients with $\mathrm{MCI}$ or $\mathrm{AD}$, and in healthy controls. The results indicated that $\mathrm{N}$-terminal pro-brain natriuretic peptide (NT-proBNT) was significantly increased in patients with $\mathrm{MCI}$ or $\mathrm{AD}$, and could be considered a potential biomarker for AD diagnosis and prognosis (25). Multiplex assays were used to measure 26 previously discovered $\mathrm{AD}$-associated plasma biomarkers in plasma samples from patients with $\mathrm{AD}$ and MCI, and elderly non-demented individuals from three multicenter cohorts. These assays demonstrated that 10 proteins, namely transthyretin (TTR), clusterin, cystatin C, alpha-1-acid glycoprotein, intercellular adhesion molecule 1 , complement $\mathrm{C} 4$, pigment epithelium-derived factor (PEDF), alpha-1 antitrypsin, normal $\mathrm{T}$ cells, and expressed and secreted Apolipoprotein C3, were strongly associated with the severity and progression of AD. The 10 proteins, plus the Apolipoproteina E (ApoE) genotype, had the greatest predictive power for identifying dementia from prodromal disease (26). In addition, butyrylcholinesterase K-variant alleles had synergistic effects with the APOE $\varepsilon 4$ genotype on the conversion of MCI to AD (27). Another study measured the levels of 146 plasma proteins at baseline and after 1 year using a multiplex immunoassay panel; the results verified that the levels of eotaxin 3, pancreatic polypeptide and NT-proBNT were increased in subjects with $\mathrm{AD}$ and $\mathrm{MCI}$, which was similar to changes detected in the CSF, and also demonstrated that the Apo $\varepsilon 3 / \varepsilon 4$ or $\varepsilon 4 / \varepsilon 4$ genotype depended on the biochemical profile (28). Another study quantified 1,001 proteins by SOMAscan, and demonstrated that protein expression levels of prostate-specific antigen complexed to $\alpha 1$-antichymotrypsin, pancreatic prohormone, clusterin and fetuin B were the most strongly associated with AD. Pancreatic prohormone was significantly associated with left entorhinal cortex and hippocampus atrophy, whereas fetuin B was only related to left entorhinal atrophy. Clusterin was significantly related to the rate of cognitive decline (29).

Other potential blood-derived markers include mitochondrial function indicator $\mathrm{N}$-acetylaspartate (NAA), neuroinflammatory indicator chitinase-3-like 1 (YKL-40), stress protein heme oxygenase-1 (HO-1), nutritional biomarkers, histone-binding protein $\mathrm{RbAp} 48$, plasma ketone body (KB), and a cumulative risk index based on several pathways associated with cognitive decline for blood-derived markers. NAA levels are coupled to neuronal mitochondrial function and are correlated with $\mathrm{A} \beta 42$ in patients with $\mathrm{AD}(30)$. The mean plasma and CSF levels of YKL-40 were enhanced in individuals with a clinical dementia rating between 0.5 and 1, and YKL-40 is considered a potential fluid biomarker for preclinical AD (31). HO-1 protein levels in plasma and CSF, and mRNA levels of lymphocyte HO-1 in individuals with sporadic AD are decreased compared with in normal controls, and other subjects with chronic neurological and medical disorders (32). A previous study suggested that plasma levels of $\alpha$ - $/ \gamma$-tocopherols, or plasma levels of $\gamma$-tocotrienols in combination with structural magnetic resonance imaging (sMRI) measures, may be used to differentiate patients with 


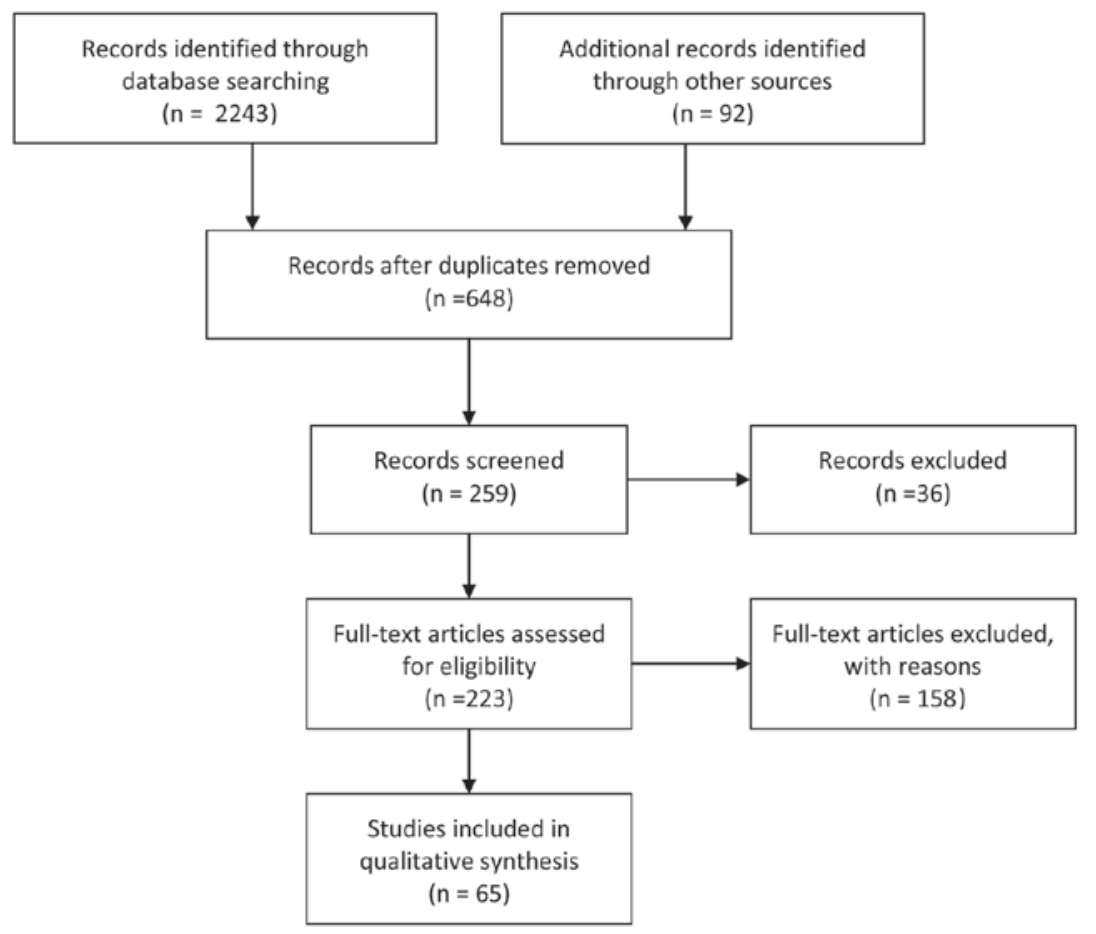

Figure 1. Flowchart of the screening of articles related to potential fluid biomarkers for pathological brain alterations in Alzheimer's disease.

$\mathrm{AD}$ or MCI from cognitively healthy individuals, and predict the conversion of MCI to AD after 1 year of follow-up (33). High levels of homocysteine, a risk factor for microvascular impairment, have been associated with alterations in electroencephalographic rhythms in mild $\mathrm{AD}$, but not in MCI subjects, including unselective increases in cortical delta, theta and alpha rhythms (34). Compared with control individuals, plasma levels of non-enzymatic and enzymatic antioxidants were similarly decreased in patients with $\mathrm{MCI}$ and $\mathrm{AD}$ (35). Baseline higher levels of free copper may be used to predict severe cognitive decline in $\mathrm{AD}$, and a faster and more obvious progression of disability at 1 year (36). Patients with higher levels of free copper combined with hyperlipidemia were also prone to severe cognitive impairment. RbAp48 modifies histone acylation and is associated with age-related memory impairment. Post-mortem measures demonstrated that levels of RbAp48, which are associated with hippocampus-dependent memory deficits in elderly individuals, were decreased in the dentate gyrus. Similar memory deficits were also observed in RbAp48-deficient transgenic mice (37). Unlike the amyloid cascade hypothesis, which suggests that amyloid pathways are the main therapeutic target, the interventions based on the mitochondrial cascade hypothesis, which suggests that mitochondrial function decline triggers AD pathophysiological cascade, are associated with the restoration and maintenance of mitochondrial function. The increase in plasma KB levels induced by ketone ester in several animal models of AD may improve mitochondrial metabolism and postpone the appearance of AD-like pathological alterations (38). Therefore, low plasma KB levels may be a potential biomarker for AD pathology in individuals with preclinical sporadic $\mathrm{AD}$ or reversible $\mathrm{CF}$. A cummulative risk index, including blood-derived markers ApoE $\varepsilon 4$ and $\mathrm{A} \beta 42 / 40$, telomere length, blood glucose, cystatin, C-reactive protein, interleukin (IL)-6 and albumin (39), may provide valuable predictive information regarding future cognitive trajectories independent of age and baseline cognitive status. It is a question worthy of further research whether this same risk index could also predict CF. In addition, the ApoE genotype, IL-6 receptor and clusterin plasma levels, together with Auditory-Verbal Learning Test and Trails B have been reported to be useful for predicting brain amyloidosis and MCI progression to $\mathrm{AD}$ with modest accuracy (40). In genetic analyses of non-familial AD, the ApoE $\varepsilon 4$ genotype contributes to the heterogeneity of disease processes associated with sporadic $\mathrm{AD}$ (41-43). In addition, alongside the ApoE receptor, the low density lipoprotein receptor 5 repeated allele has been reported to be associated with the risk of dementia, and the correlation was more evident in individuals with mixed or vascular dementia (VaD) compared with $\mathrm{AD}(44)$.

Potential CSF-derived markers of $A D$ and MCI. The $\mathrm{CSF}-$ derived biomarkers for $\mathrm{AD}$ and $\mathrm{MCI}$ are presented in Table II. The monomer form A $\beta 42$, tau and phosphorylated (p)-tau are widely used to screen $\mathrm{AD}$ and $\mathrm{MCI}$ caused by $\mathrm{AD}$, and to predict the conversion of preclinical $\mathrm{AD}$ and $\mathrm{MCI}$ to AD $(45,46)$, independent of the ApoE genotype (43). Among the CSF biomarkers, CSF A $\beta 42$ has been reported to have the best diagnostic accuracy for the discrimination of AD from frontotemporal dementia (47). CSF A $\beta 42$ and florbetapir were inversely correlated across cognitively normal, $\mathrm{MCI}$ and $\mathrm{AD}$ groups with $86 \%$ consistency (48). Abnormal CSF A $\beta$ levels together with abnormal imaging and serum markers exhibited a better predictive value for the earliest stage of AD (49). Individuals with abnormal CSF proteins, particularly abnormalities of both tau and A $\beta 42$ appeared to be simultaneously at greatest risk of cognitive decline (50) and progression from MCI into incipient AD (51). In addition, the p-tau/A $\beta 42$ ratio 


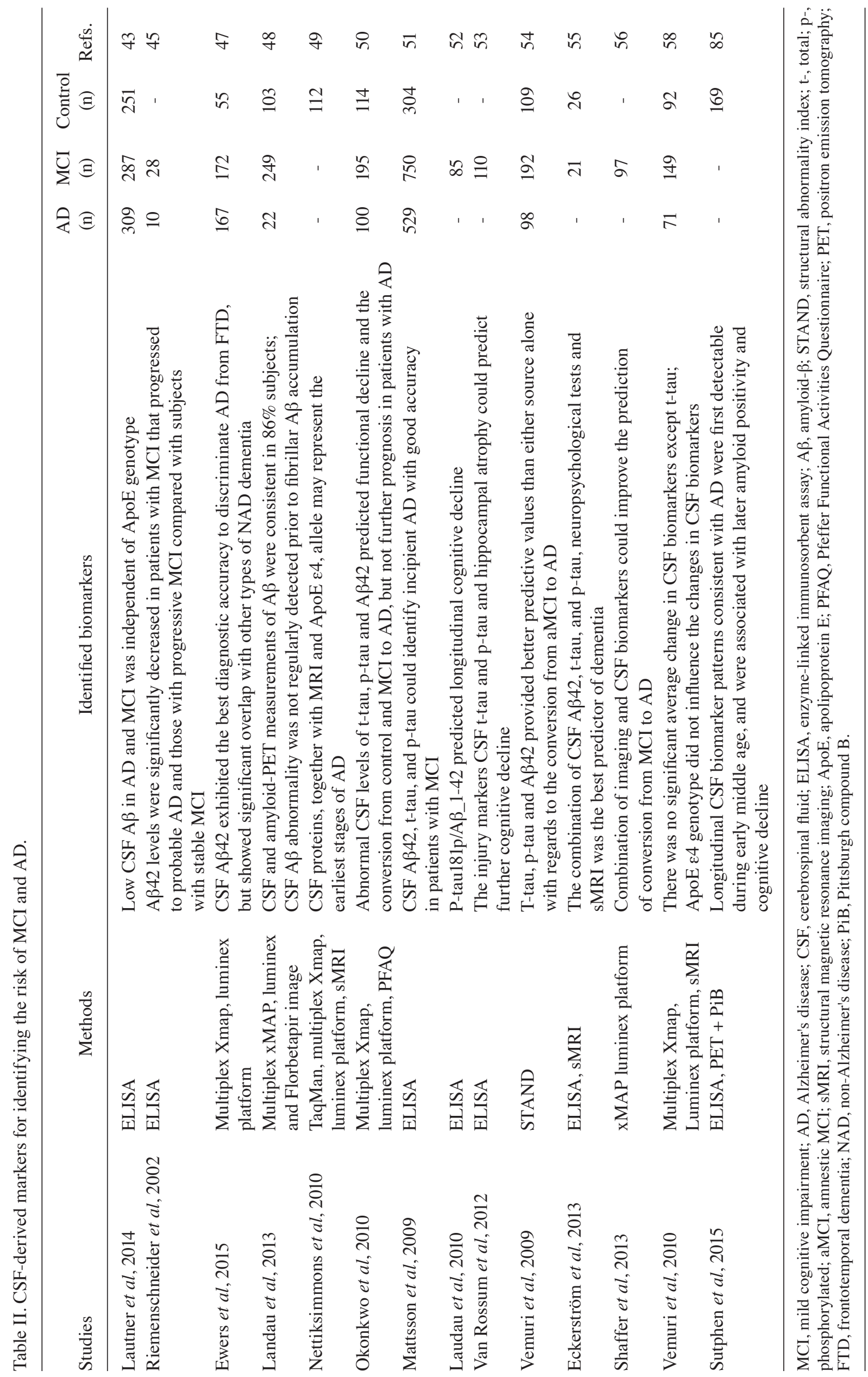


in CSF could longitudinally predict cognitive performance loss in subjects with MCI (52). Injury markers in CSF, including total (t)-tau and $\mathrm{p}$-tau, could also predict conversion time, from MCI with amyloid pathology, to dementia (53). However, MRI was slightly better at predicting future clinically defined disease stages and functional decline compared with A $\beta 42$, tau or p-tau in the CSF (54). A combination of MRI or fluorodeoxyglucose-positron emission tomography and CSF promote the predictive value of the conversion of MCI to AD $(55,56)$. However, a combination of CSF $\mathrm{t}$-tau/A $\beta 42$ together with sMRI or neuropsychological tests was not superior, as compared with single trail making test-B or sMRI measures of the right entorhinal cortex (57). Unlike the evaluated CSF values of t-tau, $\mathrm{p}$-tau and $\mathrm{A} \beta 42$, the order of the annual increase in ventricular volume detected by serial sMRI was AD group $>$ amnestic MCI group $>$ no AD group. Furthermore, the annual increase in ventricular volume was consistent with the annual decrease in general cognitive and functional indices. The alterations in structure and cognitive function were influenced by the ApoE $\varepsilon 4$ genotype (58).

The potentially associated CSF-derived biomarkers for $\mathrm{AD}$ and MCI are presented in Table III. A previous study reported that the albumin ratio between CSF and serum is normal in patients with AD independent of age, and is increased in patients with cerebrovascular diseases (59). However, an elevation in the ratio was associated with AD and $\mathrm{VaD}$ in an 85-year-old population, and was associated with the conversion from non-dementia to dementia across 3 years of follow-up (60). A previous study indicated that age-dependent elevation in the ratio could be observed in ApoE $\varepsilon 4$ allele carriers without cognitive impairment (61). An elevation in the albumin ratio was also closely associated with severity in patients with $\mathrm{AD}$ with medial temporal atrophy (62). Another study demonstrated that an age-dependent elevation in the ratio could only be detected in the hippocampal CA1 and dentate gyrus regions of cognitively normal subjects (63). Compared with cognitively normal subjects, patients with MCI exhibited an increase in the ratio and the levels of soluble platelet-derived growth factor receptor- $\beta$. These biomarkers of neurovascular unit damage appeared earlier than other biomarkers, including CSF A $\beta 42$ and tau. Increased CSF $\beta$-secretase (BACE 1) activity in individuals with sporadic $\mathrm{AD}$ may be involved in the amyloidogenic process and axonal degeneration (64). Elevated BACE 1 activity in subjects with $\mathrm{AD}$ and $\mathrm{MCI}$ has been shown to be associated with the ApoE $\varepsilon 4$ genotype, and decreased levels of $A \beta 42$ were only observed in ApoE $\varepsilon 4$ carriers with MCI (65). CSF levels of the soluble amyloid precursor proteins (sAPP) $\alpha$ and $\beta$ were similar between AD and healthy controls; however, sAPP $\beta$ levels were significantly higher in patients with MCI compared with healthy controls (66). Significantly higher levels of sAPP in the CSF were superior to significantly lower levels of CSF A $\beta 42$ with regards to early prediction of the progression from $\mathrm{MCI}$ to $\mathrm{AD}$, and the differential diagnosis of $\mathrm{AD}$ from $\mathrm{MCI}$ and frontotemporal dementia (67). Compared with the stable MCI group and the control group, the levels of sAPP $\alpha$ and $\beta$ were significantly higher in the $\mathrm{AD}$ group and the $\mathrm{MCI}$ progression to $\mathrm{AD}$ group; the ApoE $\varepsilon 4$ allele had no effects on the levels of sAPP $\alpha$ and $\beta$ (68). CSF A $\beta 42 / A \beta 40$ values were more sensitive than CSF levels of $A \beta 42$ for the identification of incipient AD in MCI individuals (69). Soluble A $\beta$ oligomers are potential biomarkers for $\mathrm{AD}$; however, compared with the changes in CSF A $\beta 42$ or tau, changes in the levels of soluble oligomers were not superior for the discrimination of $\mathrm{AD}$ from controls $(70,71)$. In a comparative study of brain expression of soluble $A \beta$ oligomers, $A \beta \times 56$, and $A \beta$ trimers and dimers, it was demonstrated that levels of $A \beta$ dimers were highest in subjects with probable $\mathrm{AD}$, and the levels of $\mathrm{A} \beta \times 56$ and $\mathrm{A} \beta$ trimers were lowest when compared with age-matched unimpaired and young unimpaired subjects (72). Furthermore, only A $\beta \times 56$ was correlated with pathological tau proteins and postsynaptic proteins. These results suggested that $\mathrm{A} \beta \mathrm{x} 56$ may contribute to the very early stages of AD pathogenesis. Savage et al reported that higher $A \beta$ oligomer levels predicted more severe dementia (73). However, analogous to the detection of various monomer forms, including $A \beta 40$ and $A \beta 42$, developing even more specific assays to measure the precise nature of oligomers via more sensitive amplification platforms will improve the early diagnostic potential of these biomarkers (74). The amide I band reflects the structural destruction of all types of $\mathrm{A} \beta$ peptides. Its downshift in CSF and blood has been detected in patients with $\mathrm{MCI}$ that progressed to $\mathrm{AD}$, and its downshift frequency was superior to a single $A \beta$ misfold or the level of specific oligomers (75).

Synaptic biomarkers in the CSF are potential early biomarkers for AD. Neurogranin, which is mainly located in dendritic spines, is associated with long-term potentiation and memory consolidation. CSF neurogranin is composed of a series of C-terminal peptides. All neurogranin peptides detected by the ELISA method suggest that CSF neurogranin may be used to monitor synaptic degeneration and reflect the rate of cognitive decline in individuals with prodromal AD (76). Even if it is very rare in CSF, the levels of CSF neurogranin peptide 48-76 exhibit the most obvious increase in patients with $\mathrm{AD}$. A progressive decline in CSF levels of neurogranin could be observed from individuals with $\mathrm{AD}, \mathrm{MCI}$ that progressed to $\mathrm{AD}$, stable MCI to controls (77). Patients with $\mathrm{AD}$ or $\mathrm{MCI}$ that progressed to $\mathrm{AD}$ demonstrated significantly higher baseline CSF levels of neurogranin compared with stable MCI or controls (77,78). CSF levels of the cytoskeleton light neurofilament protein were significantly higher in patients with late-onset AD or frontotemporal dementia compared with controls (79). In addition, alterations in the CSF levels of axonal growth-associated protein-43 were associated with changes in CSF tau and sAPP levels, and patients with $\mathrm{AD}$ exhibited a significant increase compared with controls (80). However, the detection of specific peptides and other biomarkers for synaptic dysfunction will benefit from the development of novel ultrasensitive assays.

The onset of cognitive decline is estimated to lag AD pathology by $10-15$ years. By the time of the appearance of clinically detectable cognitive impairment, substantial neuronal loss has occurred. As a marker of neuronal damage, the AD-associated neuronal thread protein AD7c-NTP is a $\sim 41 \mathrm{kD}$ membrane-spanning phosphoprotein. The increase in immunoreactive AD7c-NTP in the brain is associated with the increase in p-tau-immunoreactive cytoskeletal lesions, but not the increase in $\mathrm{A} \beta$ accumulation. The protein may be involved in neuronal apoptosis and neurite sprouting, and in the pathological alterations of AD. Dying cells in the brain are 


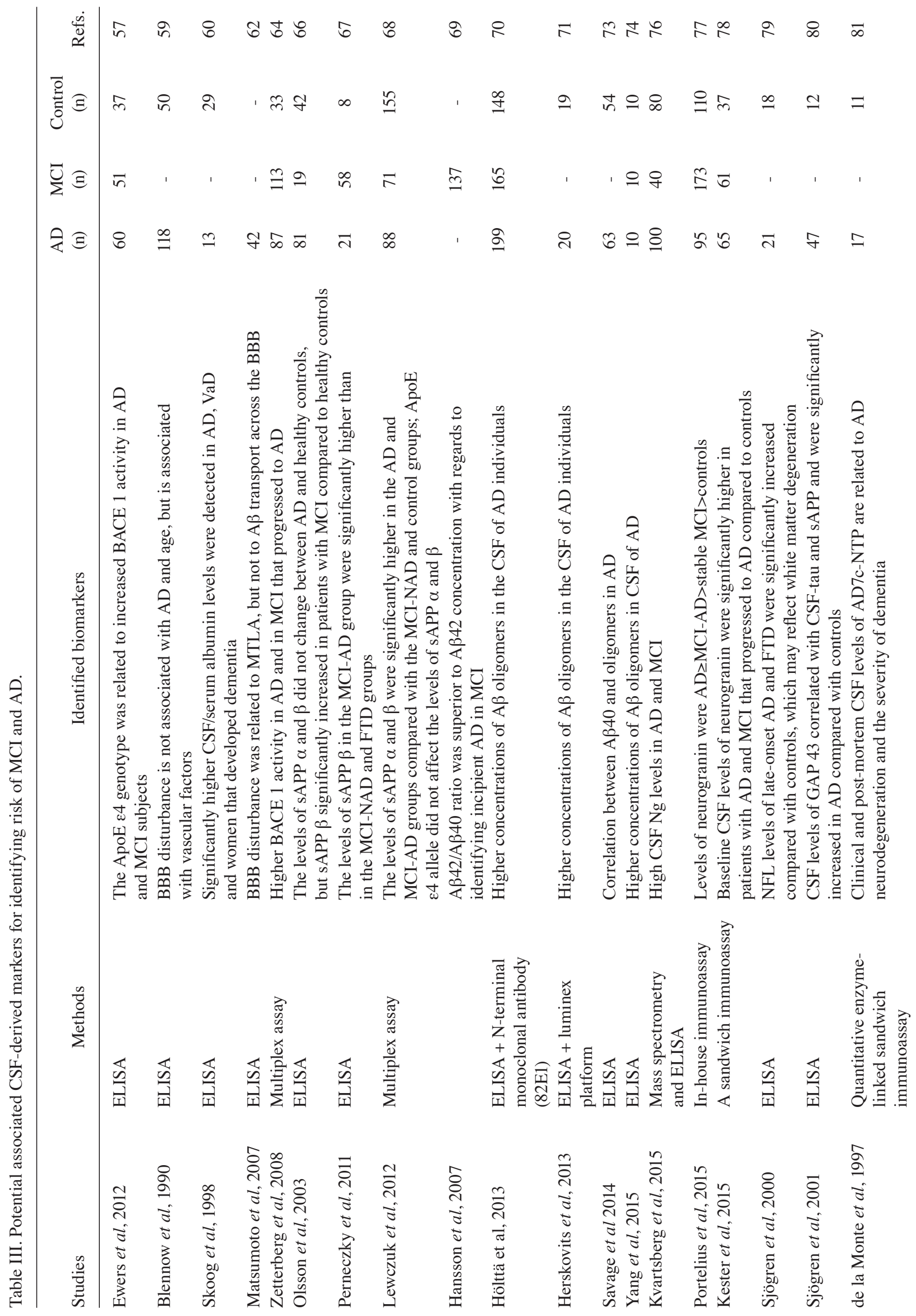




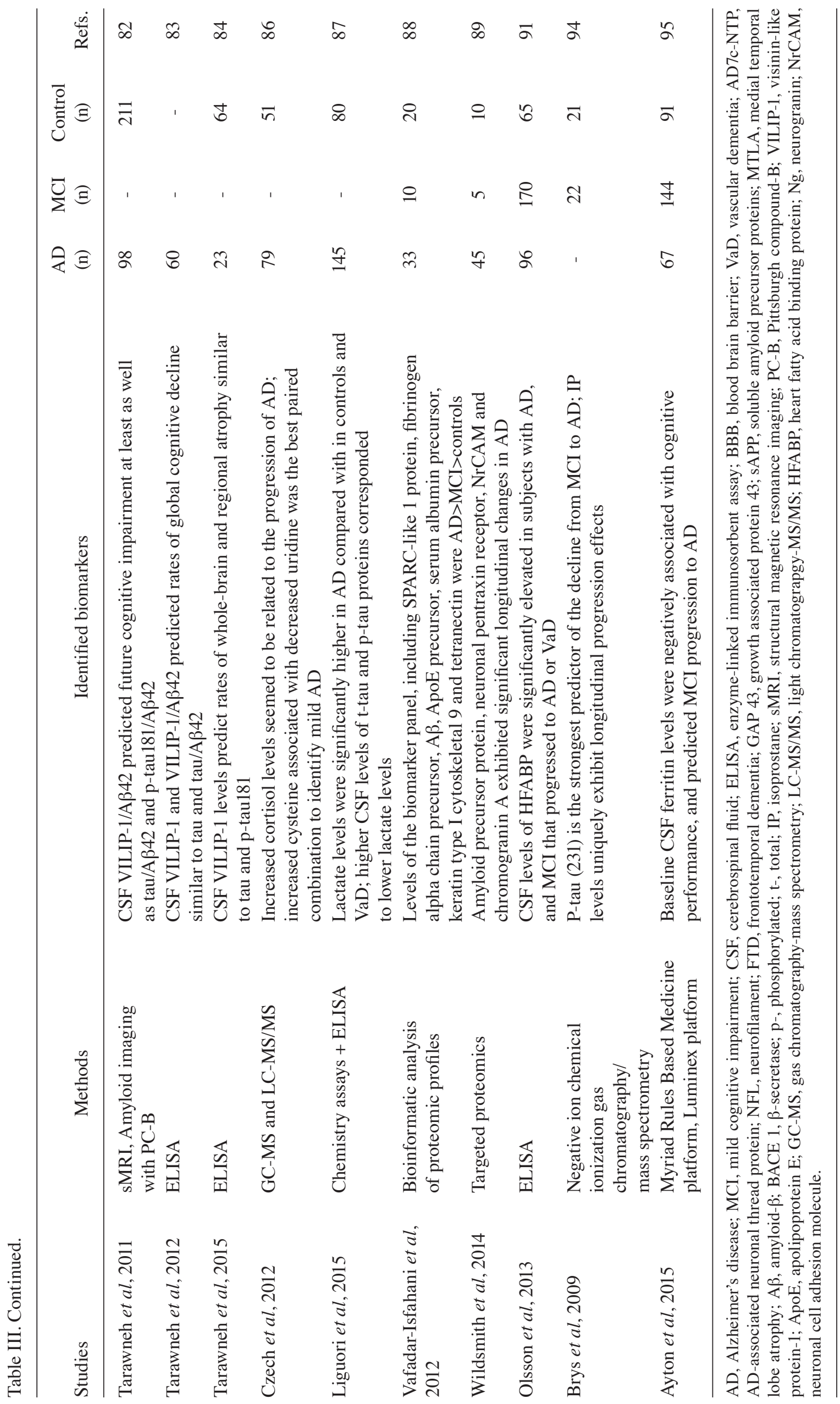


able to secrete or release the protein into the CSF. Post-mortem CSF levels of AD7c-NTP in AD were significantly higher compared with in age-matched controls. The CSF levels of patients with probable AD were also significantly higher compared with controls or other neurological disease controls, and were associated with the severity of cognitive impairment (81). The CSF levels of visinin-like protein-1 (VILIP-1) and the ratios of VILIP-1/A $\beta 42$, similar to tau and tau/A $\beta$, may predict future cognitive decline in cognitively normal subjects, differentiate patients with AD from non-AD dementia and healthy controls (82), and predict rates of global cognitive decline in individuals with early AD (83). CSF VILIP-1 levels may also predict rates of whole-brain and regional atrophy with a similar power to CSF levels of tau and p-tau181 in individuals with very mild AD or preclinical AD (84). Longitudinal CSF biomarker patterns, including low A $\beta 42$ in early middle age, markedly increased t-tau, p-tau and VILIP-1 in mid- and late middle age, and increased levels of the neuroinflammatory marker YKL-40 throughout middle age, were useful for screening middle-aged, asymptomatic individuals with $\mathrm{AD}(85)$.

Systematic analysis of metabolite profiling of the CSF by magnetic resonance spectroscopy demonstrated that increased cortisol and cysteine levels, and decreased uridine levels, may be involved in the progression of AD. Individuals with severe AD exhibited increased cortisol levels, and individuals with mild AD [Mini Mental State Examination (MMSE) $>22$ ] exhibited increased cysteine and decreased uridine levels. Specificity and sensitivity $>75 \%$ could be obtained for the paired combination of cysteine and uridine to identify mild AD (86). Lactate is a product of glycolytic metabolism; CSF levels of lactate in patients with AD were significantly higher compared with in controls and $\mathrm{VaD}$ controls (87). Patients with mild AD exhibited higher lactate levels compared with in moderate and severe $\mathrm{AD}$, and higher lactate levels corresponded with lower levels of $\mathrm{t}$-tau and $\mathrm{p}$-tau. A biomarker panel that analyzed the levels of seven proteins in the CSF by proteomic analysis and mass spectroscopy was able to classify AD individuals from controls with an accuracy of $84.5 \%$ (sensitivity $93.3 \%$, specificity $75.7 \%$ ) (88). Target proteomic analysis detected another four proteins that could reflect obvious longitudinally dynamic alterations during AD progression (89). Other potential CSF-derived markers include $\alpha$-synuclein, heart fatty acid binding protein (HFABP), PEDF, complexed prostaglandin-d-synthase (PDS) and TTR, isoprostane and ferritin. CSF $\alpha$-synuclein levels were not only significantly increased in patients with $\mathrm{MCI}$ and $\mathrm{AD}$ compared with controls, the increase in CSF $\alpha$-synuclein levels was also significantly associated with the decrease in MMSE scores (90). CSF $\alpha$-synuclein levels only offered modest sensitivity and specificity as a diagnostic marker of AD. Significantly increased CSF levels of HFABP were detected in patients with AD compared with controls, and in patients with MCI that progressed to AD or VaD when compared with individuals with stable MCI (91). However, HFABP had a lower predictive value than $A \beta 42$, t-tau and $p$-tau in identifying the progression of MCI to $\mathrm{AD}$ and VaD. Cortical neurons and astrocytes in AD brains demonstrated strong immunostaining of PEDF, and CSF PEDF as a biomarker may improve the diagnosis of AD (92). Complexed PDS/TTR exhibited a significant increase in post-mortem ventricular CSF in MCI and late-stage AD compared with diseased control subjects, and lumbar CSF levels of the complex showed a six-fold increase in living subjects with probable AD compared with normal control subjects (93). CSF levels of isoprostane were shown to possess robust longitudinal effects on the progression of MCI to AD. The annual rate of isoprostane was significantly different in the following order: MCI that progressed to AD group>stable MCI group>controls (94). The elevated CSF levels of ferritin were not only associated with cognitive performance but could also predict AD progression (95).

Potential urinary-derived markers for $A D$ and MCI. The potential urinary-derived biomarkers for AD and MCI are presented in Table IV. Patients with AD demonstrated elevated levels of AD7c-NTP in CSF and urine, and the elevated levels of AD7c-NTP were associated with the severity of dementia, i.e., very mild, mild or moderately severe AD. Several studies have suggested that AD7c-NTP is a useful biomarker, and may be widely used to screen the risk of elderly individuals with MCI and AD (96-99).

Oxidative stress and oxidative DNA damage have important roles in the process of AD. A major product of oxidative DNA damage is 8-hydroxy-2'-deoxyguanosine (8-OHdG). The antioxidant enzyme paraoxonase 1 (PON1) is able to prevent the oxidation of low-density lipoproteins. Patients with AD exhibited significantly elevated levels of 8-OHdG in urine and significantly decreased PON1 activity in serum, as compared with in healthy elderly volunteers (100). Isoprostanes, which are products of arachidonic acid peroxidation by free radicals, are also biomarkers for oxidative injury. Urinary levels of F2-isoprostanes are significantly elevated in AD subjects (101). In addition, 3-hydroxypropyl mercapturic acid/creatinine reduction in urine is not only associated with stroke but is also an ideal biomarker for differentiating patients with $\mathrm{AD}$ from patients with MCI (102). Furthermore, high levels of urinary polyphenols may exert protective effects of polyphenol intake against cognitive impairment, and are associated with a lower risk of obvious cognitive decline in elderly individuals over a 3-year follow-up period (103).

Cell-based techniques for analyzing tau pathogenicity. Recently, two novel methods to detect tau pathogenicity have been developed. One method detects tau seeding activity in various AD brain lysates using a cell-based biosensor assay. In vitro studies have reported that pathogenic tau oligomers can move between cells similar to mechanisms of prion pathogenesis, this is referred to as transcellular spread (104). Briefly, biosensor cells are generated to express human tau proteins fused with cyan fluorescent protein (CFP) or yellow fluorescent protein (YFP); when pathogenic tau from AD samples is added to a culture of biosensor cells, which contain tau proteins fused with CFP or YFP, pathogenic tau promotes the aggregation of two fused proteins and results in a positive fluorescence resonance energy transfer signal (105). The signal intensity reflects the pathogenic tau seeding activity of the AD sample. Detection of pathogenic tau seeding activity from human brain samples could reliably differentiate AD from Huntington's disease and aged controls (106). In addi- 
tion, P301S tau transgenic mice demonstrated that tau seeding activity is an ideal biomarker of tauopathy. Increases in tau seeding activity occurred 1.5 months earlier than tau deposition. Future verification of pathogenic tau seeding activity in human CSF or blood will improve the diagnostic accuracy of tauopathies in a clinical setting, and provide a noninvasive biomarker to evaluate the therapeutic efficacy of tau-modifying agents in future clinical trials.

The second method quantitatively detects tau pathogenicity in biological samples using monoclonal antibodies against seeding tau. The antibodies can also be used as an immunotherapy that traps pathogenic tau and prevents transcellular spread. Anti-pathogenic tau antibodies that inhibit the ability for tau pathogenicity in vitro could markedly reduce the levels of p-tau, aggregated and insoluble tau, and inhibit microglial activation and improve cognition in P301S tau transgenic mice (107). If these antibodies can be used to quantify tau pathogenicity in CSF and blood from different individuals, they may be considered potentially noninvasive biomarkers for detecting tau pathology.

Implications for CF screening. Aging-related major neurocognitive disorders, particularly AD-induced neurodegeneration, can progress over decades before clinical symptoms become apparent. Biomarkers for brain pathological processes allow for their early diagnosis in preclinical stages and for the development of objective prognostic assessments in clinical intervention trials. Some fluid biomarkers, including $A \beta 42$, $t$-tau and $p$-tau, have been widely used in clinical practice and clinical trials. The development of novel measurement techniques greatly promotes the production of novel biomarkers and improves the accuracy of old biomarkers $(19,20,73,74)$. Several novel biomarkers associated with different aspects of AD neuropathology are being developed, including those related to synaptic dysfunction, neuronal damage and apoptosis, neuronal activity alteration, neuroinflammation, oxidative stress, metabolites, mitochondrial function and aberrant lipid metabolism. A bioinformatics approach for identifying specific single nucleotide polymorphisms (108-110) and epigenetic markers, including microRNAs (111) in the CSF or blood of patients with MCI, AD or non-AD dementia may also be useful for $\mathrm{AD}$ diagnosis and differentiation.

Based on the ordering of AD biomarkers, particularly CSF biomarkers (A $\beta 42$, t-tau and $p$-tau), and AD-associated biomarkers, such as neural injury and neuroinflammation biomarkers, we classified which one was the earliest event resulting in the heterogeneity of cognitive impairment. These biomarkers may be helpful for the diagnosis of $\mathrm{CF}$ and the differential diagnosis of cognitive impairment from $\mathrm{CF}$, including $\mathrm{AD}$ or $\mathrm{VaD}$. CF consists of reversible and potentially reversible cognitive impairment subtypes (112). The former is based on SCD, and the latter is comparable to MCI. The most common cause of cognitive impairment of $\mathrm{CF}$ is $\mathrm{AD}$. The severity of SCD has been associated with biomarkers for $\mathrm{AD}$ in subjects with MCI, including low CSF A $\beta 42$ and high CSF tau or p-tau levels (46). Longitudinal CSF biomarkers, such as A $\beta 42$ reductions in early middle age; markedly increased tau, p-tau and VILIP-1 in mid- and late middle age, and increases in YKL-40 throughout middle age were associated with the 
severity of cognitive impairment in prelinical AD (85). The combination of fluid biomarkers and imaging biomarkers could further improve diagnostic accuracy of cognitive impairment. In addition, physical frailty and AD may share similar pathophysiological mechanisms. Certain AD-associated fluid biomarkers, such as oxidative stress and inflammatory markers, may also contribute to the screening of physical frailty in CF subjects $(112,113)$. Furthermore, the dynamic changes of AD-specific and AD-associated fluid biomarkers may be helpful for the screening of candidate drugs that affect cognitive impairment and physical frailty.

\section{Acknowledgements}

The present study was supported by grants from the Shanghai Hospital Development Center (grant no. SHDC12014221) and the Shanghai Key Laboratory of Clinical Geriatric Medicine (grant no. 13dz2260700).

\section{References}

1. Kelaiditi E, Cesari M, Canevelli M, van Kan GA, Ousset PJ, Gillette-Guyonnet S, Ritz P, Duveau F, Soto ME, Provencher V, et al: Cognitive frailty: Rational and definition from an (I.A.N.A./I.A.G.G.) international consensus group. J Nutr Health Aging 17: 726-734, 2013.

2. Ruan Q, Yu Z, Chen M, Bao Z, Li J and He W: Cognitive frailty, a novel target for the prevention of elderly dependency. Ageing Res Rev 20: 1-10, 2015.

3. Buerger K, Frisoni G, Uspenskaya O, Ewers M, Zetterberg H, Geroldi C, Binetti G, Johannsen P, Rossini PM, Wahlund LO, et al: Validation of Alzheimer's disease CSF and plasma biological markers: The multicentre reliability study of the pilot European Alzheimer's disease neuroimaging initiative (E-ADNI). Exp Gerontol 44: 579-585, 2009.

4. Yang T, Hong S, O'Malley T, Sperling RA, Walsh DM and Selkoe DJ: New ELISAs with high specificity for soluble oligomers of amyloid $\beta$-protein detect natural $A \beta$ oligomers in human brain but not CSF. Alzheimers Dement 9: 99-112, 2013.

5. Dixon-Woods M, Agarwal S, Jones D, Young B and Sutton A: Synthesising qualitative and quantitative evidence: A review of possible methods. J Health Serv Res Policy 10: 45-53, 2005.

6. Hannes K and Macaitis K: A move to more systematic and transparent approaches in qualitative evidence synthesis: Update on a review of published papers. Qual Res 12: 402-442, 2012.

7. McKhann GM, Knopman DS, Chertkow H, Hyman BT, Jack CR Jr, Kawas CH, Klunk WE, Koroshetz WJ, Manly JJ, Mayeux R, et al: The diagnosis of dementia due to Alzheimer's disease: Recommendations from the national institute on Aging-Alzheimer's association workgroups on diagnostic guidelines for Alzheimer's disease. Alzheimers Dement 7: 263-269, 2011.

8. Albert MS, DeKosky ST, Dickson D, Dubois B, Feldman HH, Fox NC, Gamst A, Holtzman DM, Jagust WJ, Petersen RC, et al: The diagnosis of mild cognitive impairment due to Alzheimer's disease: Recommendations from the national institute on Aging-Alzheimer's association workgroups on diagnostic guidelines for Alzheimer's disease. Alzheimers Dement 7: 270-279, 2011.

9. Barnett-Page E and Thomas J: Methods for the synthesis of qualitative research: A critical review. BMC Med Res Methodol 9: 59, 2009.

10. Grant MJ and Booth A: A typology of reviews: An analysis of 14 review types and associated methodologies. Health Info Libr J 26: 91-108, 2009.

11. Noel-Storr AH, McCleery JM, Richard E, Ritchie CW, Flicker L, Cullum SJ, Davis D, Quinn TJ, Hyde C, Rutjes AW, et al: Reporting standards for studies of diagnostic test accuracy in dementia: The STARDdem Initiative. Neurology 83 : 364-373, 2014.
12. Padovani A, Borroni B, Colciaghi F, Pettenati C, Cottini E, Agosti C, Lenzi GL, Caltagirone C, Trabucchi M, Cattabeni F and Di Luca M: Abnormalities in the pattern of platelet amyloid precursor protein forms in patients with mild cognitive impairment and Alzheimer disease. Arch Neurol 59: 71-75, 2002

13. Borroni B, Colciaghi F, Caltagirone C, Rozzini L, Broglio L, Cattabeni F, Di Luca M and Padovani A: Platelet amyloid precursor protein abnormalities in mild cognitive impairment predict conversion to dementia of Alzheimer type: A 2-year follow-up study. Arch Neurol 60: 1740-1744, 2003.

14. Baskin F, Rosenberg RN, Iyer L, Hynan L and Cullum CM: Platelet APP isoform ratios correlate with declining cognition in AD. Neurology 54: 1907-1909, 2000.

15. Prodan CI, Ross ED, Stoner JA, Cowan LD, Vincent AS and Dale GL: Coated-platelet levels and progression from mild cognitive impairment to Alzheimer disease. Neurology 76: 247-252, 2011

16. Lewczuk P, Kornhuber J, Vanmechelen E, Peters O, Heuser I, Maier W, Jessen F, Bürger K, Hampel H, Frölich L, et al: Amyloid beta peptides in plasma in early diagnosis of Alzheimer's disease: A multicenter study with multiplexing. Exp Neurol 223: 366-370, 2010.

17. Gurol ME, Irizarry MC, Smith EE, Raju S, Diaz-Arrastia R, Bottiglieri T, Rosand J, Growdon JH and Greenberg SM: Plasma beta-amyloid and white matter lesions in AD, MCI, and cerebral amyloid angiopathy. Neurology 66: 23-29, 2006.

18. Lopez OL, Kuller LH, Mehta PD, Becker JT, Gach HM, Sweet RA, Chang YF, Tracy R and DeKosky ST: Plasma amyloid levels and the risk of AD in normal subjects in the cardiovascular health study. Neurology 70: 1664-1671, 2008.

19. Rissin DM, Kan CW, Campbell TG, Howes SC, Fournier DR, Song L, Piech T, Patel PP, Chang L, Rivnak AJ, et al: Single-molecule enzyme-linked immunosorbent assay detects serum proteins at subfemtomolar concentrations. Nat Biotechnol 28: 595-599, 2010.

20. Zetterberg H, Wilson D, Andreasson U, Minthon L, Blennow K, Randall J and Hansson O: Plasma tau levels in Alzheimer's disease. Alzheimers Res Ther 5: 9, 2013

21. Zhang Z, Song M, Liu X, Kang SS, Kwon IS, Duong DM, Seyfried NT, Hu WT, Liu Z, Wang JZ, et al: Cleavage of tau by asparagine endopeptidase mediates the neurofibrillary pathology in Alzheimer's disease. Nat Med 20: 1254-1262, 2014.

22. Mapstone M, Cheema AK, Fiandaca MS, Zhong X, Mhyre TR, MacArthur LH, Hall WJ, Fisher SG, Peterson DR, Haley JM, et al: Plasma phospholipids identify antecedent memory impairment in older adults. Nat Med 20: 415-418, 2014.

23. Whiley L, Sen A, Heaton J, Proitsi P, García-Gómez D, Leung R, Smith N, Thambisetty M, Kloszewska I, Mecocci P, et al: Evidence of altered phosphatidylcholine metabolism in Alzheimer's disease. Neurobiol Aging 35: 271-278, 2014.

24. Nitsch RM, Blusztajn JK, Pittas AG, Slack BE, Growdon JH and Wurtman RJ: Evidence for a membrane defect in Alzheimer disease brain. Proc Natl Acad Sci USA 89: 1671-1675, 1992.

25. Marksteiner J, Imarhiagbe D, Defrancesco M, Deisenhammer EA, Kemmler G and Humpel C: Analysis of 27 vascular-related proteins reveals that NT-proBNP is a potential biomarker for Alzheimer's disease and mild cognitive impairment: A pilot-study. Exp Gerontol 50: 114-121, 2014.

26. Hye A, Riddoch-Contreras J, Baird AL, Ashton NJ, Bazenet C, Leung R, Westman E, Simmons A, Dobson R, Sattlecker M, et al: Plasma proteins predict conversion to dementia from prodromal disease. Alzheimers Dement 10: 799-807.e2, 2014.

27. Lane R, Feldman HH, Meyer J, He Y, Ferris SH, Nordberg A, Darreh-Shori T, Soininen H, Pirttilä T, Farlow MR, et al: Synergistic effect of apolipoprotein E epsilon4 and butyrylcholinesterase $\mathrm{K}$-variant on progression from mild cognitive impairment to Alzheimer's disease. Pharmacogenet Genomics 18: 289-298, 2008.

28. Soares HD, Potter WZ, Pickering E, Kuhn M, Immermann FW, Shera DM, Ferm M, Dean RA, Simon AJ, Swenson F, et al: Plasma biomarkers associated with the apolipoprotein E genotype and Alzheimer disease. Arch Neurol 69: 1310-1317, 2012 .

29. Sattlecker M, Kiddle SJ, Newhouse S, Proitsi P, Nelson S, Williams S, Johnston C, Killick R, Simmons A, Westman E, et al: Alzheimer's disease biomarker discovery using SOMAscan multiplexed protein technology. Alzheimers Dement 10: 724-734, 2014. 
30. Jessen F, Lewczuk P, Gür O, Block W, Ende G, Frölich L, Hammen T, Arlt S, Kornhuber J, Kucinski T, et al: Association of N-acetylaspartate and cerebrospinal fluid $\mathrm{A} \beta 42$ in dementia. J Alzheimers Dis 27: 393-399, 2011.

31. Craig-Schapiro R, Perrin RJ, Roe CM, Xiong C, Carter D, Cairns NJ, Mintun MA, Peskind ER, Li G, Galasko DR, et al YKL-40: A novel prognostic fluid biomarker for preclinical Alzheimer's disease. Biol Psychiatry 68: 903-912, 2010.

32. Schipper HM, Chertkow H, Mehindate K, Frankel D, Melmed C and Bergman $\mathrm{H}$ : Evaluation of heme oxygenase-1 as a systemic biological marker of sporadic AD. Neurology 54: 1297-1304, 2000 .

33. Mangialasche F, Westman E, Kivipelto M, Muehlboeck JS, Cecchetti R, Baglioni M, Tarducci R, Gobbi G, Floridi P, Soininen $\mathrm{H}$, et al: Classification and prediction of clinical diagnosis of Alzheimer's disease based on MRI and plasma measures of $\alpha-/ \gamma$-tocotrienols and $\gamma$-tocopherol. J Intern Med 273: 602-621, 2013.

34. Babiloni C, Bosco P, Ghidoni R, Del Percio C, Squitti R, Binetti G, Benussi L, Ferri R, Frisoni G, Lanuzza B, et al: Homocysteine and electroencephalographic rhythms in Alzheimer disease: A multicentric study. Neuroscience 145 942-954, 2007.

35. Rinaldi P, Polidori MC, Metastasio A, Mariani E, Mattioli P, Cherubini A, Catani M, Cecchetti R, Senin U and Mecocci P. Plasma antioxidants are similarly depleted in mild cognitive impairment and in Alzheimer's disease. Neurobiol Aging 24: 915-919, 2003.

36. Squitti R, Bressi F, Pasqualetti P, Bonomini C, Ghidoni R, Binetti G, Cassetta E, Moffa F, Ventriglia M, Vernieri F and Rossini PM: Longitudinal prognostic value of serum 'free' copper in patients with Alzheimer disease. Neurology 72: 50-55, 2009.

37. Pavlopoulos E, Jones S, Kosmidis S, Close M, Kim C, Kovalerchik O, Small SA and Kandel ER: Molecular mechanism for age-related memory loss: The histone-binding protein RbAp48. Sci Transl Med 5: 200ra115, 2013.

38. HertzL, Chen Y and Waagepetersen HS: Effects of ketone bodies in Alzheimer's disease in relation to neural hypometabolism, $\beta$-amyloid toxicity, and astrocyte function. J Neurochem 134: 7-20, 2015.

39. Nettiksimmons J, Ayonayon H, Harris T, Phillips C, Rosano C, Satterfield S and Yaffe K; Health ABC Study: Development and validation of risk index for cognitive decline using blood-derived markers. Neurology 84: 696-702, 2015.

40. Apostolova LG, Hwang KS, Avila D, Elashoff D, Kohannim O, Teng E, Sokolow S, Jack CR, Jagust WJ, Shaw L, et al: Brain amyloidosis ascertainment from cognitive, imaging, and peripheral blood protein measures. Neurology 84: 729-737, 2015.

41. Smits LL, Pijnenburg YA, van der Vlies AE, Koedam EL, Bouwman FH, Reuling IE, Scheltens $P$ and van der Flier WM Early onset APOE E4-negative Alzheimer's disease patients show faster cognitive decline on non-memory domains. Eur Neuropsychopharmacol 25: 1010-1017, 2015.

42. Michaelson DM: APOE $\varepsilon 4$ : The most prevalent yet understudied risk factor for Alzheimer's disease. Alzheimers Dement 10: 861-868, 2014.

43. Lautner R, Palmqvist S, Mattsson N, Andreasson U, Wallin A, Pålsson E, Jakobsson J, Herukka SK, Owenius R, Olsson B, et al: Apolipoprotein E genotype and the diagnostic accuracy of cerebrospinal fluid biomarkers for Alzheimer disease. JAMA Psychiatry 71: 1183-1191, 2014

44. Helbecque N, Berr C, Cottel D, Fromentin-David I, Sazdovitch V, Ricolfi F, Ducimetière P, Di Menza C and Amouyel P: VLDL receptor polymorphism, cognitive impairment, and dementia. Neurology 56: 1183-1188, 2001

45. Riemenschneider M, Lautenschlager N, Wagenpfeil S, Diehl J, Drzezga A and Kurz A: Cerebrospinal fluid tau and beta-amyloid 42 proteins identify Alzheimer disease in subjects with mild cognitive impairment. Arch Neurol 59: 1729-1734, 2002

46. Wolfsgruber S, Jessen F, Koppara A,Kleineidam L, Schmidtke K, Frölich L, Kurz A, Schulz S, Hampel H, Heuser I, et al: Subjective cognitive decline is related to CSF biomarkers of AD in patients with MCI. Neurology 84: 1261-1268, 2015.

47. Ewers M, Mattsson N, Minthon L, Molinuevo JL, Antonell A, Popp J, Jessen F, Herukka SK, Soininen H, Maetzler W, et al CSF biomarkers for the differential diagnosis of Alzheimer's disease: A large-scale international multicenter study. Alzheimers Dement 11: 1306-1315, 2015.
48. Landau SM, Lu M, Joshi AD, Pontecorvo M, Mintun MA, Trojanowski JQ, Shaw LM and Jagust WJ; Alzheimer's Disease Neuroimaging Initiative: Comparing positron emission tomography imaging and cerebrospinal fluid measurements of $\beta$-amyloid. Ann Neurol 74: 826-836, 2013.

49. Nettiksimmons J, Harvey D, Brewer J, Carmichael O, DeCarli C, Jack CR Jr, Petersen R, Shaw LM, Trojanowski JQ, Weiner MW, et al: Subtypes based on cerebrospinal fluid and magnetic resonance imaging markers in normal elderly predict cognitive decline. Neurobiol Aging 31: 1419-1428, 2010.

50. Okonkwo OC, Alosco ML, Griffith HR, Mielke MM, Shaw LM, Trojanowski JQ and Tremont G; Alzheimer's Disease Neuroimaging Initiative: Cerebrospinal fluid abnormalities and rate of decline in everyday function across the dementia spectrum: Normal aging, mild cognitive impairment and Alzheimer disease. Arch Neurol 67: 688-696, 2010.

51. Mattsson N, Zetterberg H, Hansson O, Andreasen N, Parnetti L, Jonsson M, Herukka SK, van der Flier WM, Blankenstein MA, Ewers M, et al: CSF biomarkers and incipient Alzheimer disease in patients with mild cognitive impairment. JAMA 302: 385-393, 2009.

52. Landau SM, Harvey D, Madison CM, Reiman EM, Foster NL, Aisen PS, Petersen RC, Shaw LM, Trojanowski JQ, Jack CR Jr, et al: Comparing predictors of conversion and decline in mild cognitive impairment. Neurology 75: 230-238, 2010.

53. Van Rossum IA, Vos SJ, Burns L, Knol DL, Scheltens P, Soininen $\mathrm{H}$, Wahlund LO, Hampel $\mathrm{H}$, Tsolaki M, Minthon L, et al: Injury markers predict time to dementia in subjects with MCI and amyloid pathology. Neurology 79: 1809-1816, 2012.

54. Vemuri P, Wiste HJ, Weigand SD, Shaw LM, Trojanowski JQ, Weiner MW, Knopman DS, Petersen RC and Jack CR Jr; Alzheimer's Disease Neuroimaging Initiative: MRI and CSF biomarkers in normal, MCI, and AD subjects: Predicting future clinical change. Neurology 73: 294-301, 2009.

55. Eckerström C, Olsson E, Bjerke M, Malmgren H, Edman A, Wallin A and Nordlund A: A combination of neuropsychological, neuroimaging, and cerebrospinal fluid markers predicts conversion from mild cognitive impairment to dementia. J Alzheimers Dis 36: 421-431, 2013.

56. Shaffer JL, Petrella JR, Sheldon FC, Choudhury KR, Calhoun VD, Coleman RE and Doraiswamy PM; Alzheimer's Disease Neuroimaging Initiative: Predicting cognitive decline in subjects at risk for Alzheimer disease by using combined cerebrospinalfluid, MR imaging, and PET biomarkers. Radiology 266: 583-591, 2013.

57. Ewers M, Walsh C, Trojanowski JQ, Shaw LM, Petersen RC, Jack CR Jr, Feldman HH, Bokde AL, Alexander GE, Scheltens P, et al: Prediction of conversion from mild cognitive impairment to Alzheimer's disese dementia based upon biomarkers and neuropsychological test performance. Neurobiol Aging 33: 1203-1214, 2012.

58. Vemuri P, Wiste HJ, Weigand SD, Knopman DS, Trojanowski JQ, Shaw LM, Bernstein MA, Aisen PS, Weiner M, Petersen RC, et al: Serial MRI and CSF biomarkers in normal aging, MCI, and AD. Neurology 75: 143-151, 2010.

59. Blennow K, Wallin A, Fredman P, Karlsson I, Gottfries CG and Svennerholm L: Blood-brain barrier disturbance in patients with Alzheimer's disease is related to vascular factors. Acta Neurol Scand 81: 323-326, 1990.

60. Skoog I, Wallin A, Fredman P, Hesse C, Aevarsson O, Karlsson I, Gottfries CG and Blennow K: A population study on blood-brain barrier function in 85-year-olds: Relation to Alzheimer's disease and vascular dementia. Neurology 50: 966-971, 1998.

61. Halliday MR, Pomara N, Sagare AP, Mack WJ, Frangione B and Zlokovic BV: Relationship between cyclophilin a levels and matrix metalloproteinase 9 activity in cerebrospinal fluid of cognitively normal apolipoprotein e4 carriers and blood-brain barrier breakdown. JAMA Neurol 70: 1198-1200, 2013

62. Matsumoto Y, Yanase D, Noguchi-Shinohara M, Ono K, Yoshita M and Yamada M: Blood-brain barrier permeability correlates with medial temporal lobe atrophy but not with amyloid-beta protein transport across the blood-brain barrier in Alzheimer's disease. Dement Geriatr Cogn Disord 23: 241-245, 2007.

63. Montagne A, Barnes SR, Sweeney MD, Halliday MR, Sagare AP, Zhao Z, Toga AW, Jacobs RE, Liu CY, Amezcua L, et al: Blood-brain barrier breakdown in the aging human hippocampus. Neuron 85: 296-302, 2015. 
64. Zetterberg $\mathrm{H}$, Andreasson U, Hansson O, Wu G, Sankaranarayanan S, Andersson ME, Buchhave P, Londos E, Umek RM, Minthon L, et al: Elevated cerebrospinal fluid BACE1 activity in incipient Alzheimer disease. Arch Neurol 65: 1102-1107, 2008

65. Ewers M, Zhong Z, Bürger K, Wallin A, Blennow K, Teipel SJ, Shen $\mathrm{Y}$ and Hampel $\mathrm{H}$ : Increased CSF-BACE 1 activity is associated with ApoE-epsilon 4 genotype in subjects with mild cognitive impairment and Alzheimer's disease. Brain 131: 1252-1258, 2008

66. Olsson A, Höglund K, Sjögren M, Andreasen N, Minthon L, Lannfelt L, Buerger K, Möller HJ, Hampel H, Davidsson P and Blennow K: Measurement of alpha- and beta-secretase cleaved amyloid precursor protein in cerebrospinal fluid from Alzheimer patients. Exp Neurol 183: 74-80, 2003.

67. Perneczky R, Tsolakidou A, Arnold A, Diehl-Schmid J, Grimmer T, Förstl H, Kurz A and Alexopoulos P: CSF soluble amyloid precursor proteins in the diagnosis of incipient Alzheimer disease. Neurology 77: 35-38, 2011.

68. Lewczuk P, Popp J, Lelental N, Kölsch H, Maier W, Kornhuber J and Jessen F: Cerebrospinal fluid soluble amyloid- $\beta$ protein precursor as a potential novel biomarkers of Alzheimer's disease. J Alzheimers Dis 28: 119-125, 2012.

69. Hansson O, Zetterberg H, Buch have P, Andreasson U, Londos E, Minthon L and Blennow K: Prediction of Alzheimer's disease using the CSF Abeta42/Abeta40 ratio in patients with mild cognitive impairment. Dement Geriatr Cogn Disord 23: 316-320, 2007.

70. Hölttä M, Hansson O, Andreasson U, Hertze J, Minthon L, Nägga K, Andreasen N, Zetterberg $\mathrm{H}$ and Blennow $\mathrm{K}$ : Evaluating amyloid- $\beta$ oligomers in cerebrospinal fluid as a biomarker for Alzheimer's disease. PLoS One 8: e66381, 2013.

71. Herskovits AZ, Locascio JJ, Peskind ER, Li G and Hyman BT: A Luminex assay detects amyloid $\beta$ oligomers in Alzheimer's disease cerebrospinal fluid. PLoS One 8: e67898, 2013.

72. Lesne SE, Sherman MA, Grant M, Kuskowski M, Schneider JA, Bennett DA and Ashe KH: Brain amyloid- $\beta$ oligomers in ageing and Alzheimer's disease. Brain 136: 1383-1398, 2013.

73. Savage MJ, Kalinina J, Wolfe A, Tugusheva K, Korn R, Cash-Mason T, Maxwell JW, Hatcher NG, Haugabook SJ, $\mathrm{Wu} G$, et al: A sensitive a $\beta$ oligomer assay discriminates Alzheimer's and aged control cerebrospinal fluid. J Neurosci 34: 2884-2897, 2014.

74. Yang T, O'Malley TT, Kanmert D, Jerecic J, Zieske LR, Zetterberg H, Hyman BT, Walsh DM and Selkoe DJ: A highly sensitive novel immunoassay specifically detects low levels of soluble $A \beta$ oligomers in human cerebrospinal fluid. Alzheimers Res Ther 7: 14, 2015.

75. Nabers A, Ollesch J, Schartner J, Kötting C, Genius J, Hafermann $H$, Klafki $H$, Gerwert $K$ and Wiltfang $J$ Amyloid- $\beta$-secondary structure distribution in cerebrospinal fluid and blood measured by an immuno-infrared-sensor: A biomarker candidate for Alzheimer's disease. Anal Chem 88 2755-2762, 2016

76. Kvartsberg H, Duits FH, Ingelsson M, Andreasen N, Öhrfelt A, Andersson K, Brinkmalm G, Lannfelt L, Minthon L, Hansson $\mathrm{O}$, et al: Cerebrospinal fluid levels of the synaptic protein neurogranin correlates with cognitive decline in prodromal Alzheimer's disease. Alzheimers Dement 11: $1180-1190,2015$.

77. Portelius E, Zetterberg H, Skillbäck T, Törnqvist U, Andreasson U, Trojanowski JQ, Weiner MW, Shaw LM, Mattsson N and Blennow K; Alzheimer's Disease Neuroimaging Initiative: Cerebrospinal fluid neurogranin: Relation to cognition and neurodegeneration in Alzheimer's disease. Brain 138 3373-3385, 2015

78. Kester MI, Teunissen CE, Crimmins DL, Herries EM, Ladenson JH, Scheltens P, van der Flier WM, Morris JC, Holtzman DM and Fagan AM: Neurogranin as a cerebrospinal fluid biomarker for synaptic loss in symptomatic Alzheimer disease. JAMA Neurol 72: 1275-1280, 2015.

79. Sjögren M, Rosengren L, Minthon L, Davidsson P, Blennow K and Wallin A: Cytoskeleton proteins in CSF distinguish frontotemporal dementia from AD. Neurology 54: 1960-1964, 2000.

80. Sjögren M, Davidsson P, Gottfries J, Vanderstichele H, Edman A, Vanmechelen E, Wallin A and Blennow K: The cerebrospinal fluid levels of tau, growth-associated protein-43 and soluble amyloid precursor proteincorrelate in Alzheimer's disease, reflecting a common pathophysiological process. Dement Geriatr Cogn Disord 12: 257-264, 2001.
81. de la Monte SM, Ghanbari K, Frey WH, Beheshti I, Averback P, Hauser SL, Ghanbari HA and Wands JR: Characterization of the AD7C-NTP cDNA expression in Alzheimer's disease and measurement of a 41-kDprotein in cerebrospinal fluid. J Clin Invest 100: 3093-3104, 1997

82. Tarawneh R, D'Angelo G, Macy E, Xiong C, Carter D, Cairns NJ, Fagan AM, Head D, Mintun MA, Ladenson $\mathrm{JH}$, et al: Visinin-like protein-1: Diagnostic and prognostic biomarker in Alzheimer disease. Ann Neurol 70: 274-285, 2011.

83. Tarawneh R, Lee JM, Ladenson JH, Morris JC and Holtzman DM: CSF VILIP-1 predicts rates of cognitive decline in early Alzheimer disease. Neurology 78: 709-719, 2012

84. Tarawneh R, Head D, Allison S, Buckles V, Fagan AM, Ladenson JH, Morris JC and Holtzman DM: Cerebrospinal fluid markers of neurodegeneration and rates of brain atrophy in early Alzheimer disease. JAMA Neurol 72: 656-665, 2015.

85. Sutphen CL, Jasielec MS, Shah AR, Macy EM, Xiong C, Vlassenko AG, Benzinger TL, Stoops EE, Vanderstichele HM, Brix B, et al: Longitudinal cerebrospinal fluid biomarker changes in preclinical Alzheimer disease during middle age. JAMA Neurol 72: 1029-1042, 2015.

86. Czech C, Berndt P, Busch K, Schmitz O, Wiemer J, Most V, Hampel H, Kastler J and Senn H: Metabolite profiling of Alzheimer's disease cerebrospinal fluid. PLoS One 7: e31501, 2012.

87. Liguori C, Stefani A, Sancesario G, Sancesario GM, Marciani MG and Pierantozzi M: CSF lactate levels, $\tau$ proteins, cognitive decline: A dynamic relationship in Alzheimer's disease. J Neurol Neurosurg Psychiatry 86: 655-659, 2015.

88. Vafadar-Isfahani B, Ball G, Coveney C, Lemetre C, Boocock D, Minthon L, Hansson O, Miles AK, Janciauskiene SM, Warden D, et al: Identification of SPARC-like 1 protein as part of a biomarker panel for Alzheimer's disease in cerebrospinal fluid. J Alzheimers Dis 28: 625-636, 2012.

89. Wildsmith KR, Schauer SP, Smith AM, Arnott D, Zhu Y, Haznedar J, Kaur S, Mathews WR and Honigberg LA: Identification of longitudinally dynamic biomarkers in Alzheimer's disease cerebrospinal fluid by targeted proteomics. Mol Neurodegener 9: 22, 2014.

90. Korff A, Liu C, Ginghina C, Shi M and Zhang J; Alzheimer's Disease Neuroimaging Initiative: $\alpha$-Synuclein in cerebrospinal fluid of Alzheimer's disease and mild cognitive impairment. J Alzheimers Dis 36: 679-688, 2013.

91. Olsson B, Hertze J, Ohlsson M, Nägga K, Höglund K, Basun H, Annas P, Lannfelt L, Andreasen N, Minthon L, et al: Cerebrospinal fluid levels of heart fatty acid binding protein are elevated prodromally in Alzheimer's disease and vascular dementia. J Alzheimers Dis 34: 673-679, 2013.

92. Yamagishi S, Inagaki Y, Takeuchi $\mathrm{M}$ and Sasaki N: Is pigment epithelium-derived factor level in cerebrospinal fluid a promising biomarker for early diagnosis of Alzheimer's disease? Med Hypotheses 63: 115-117, 2004.

93. Lovell MA, Lynn BC, Xiong S, Quinn JF, Kaye J and Markesbery WR: An aberrant protein complex in CSF as a biomarker of Alzheimer disease. Neurology 70: 2212-2218, 2008

94. Brys M, Pirraglia E, Rich K, Rolstad S, Mosconi L, Switalski R, Glodzik-Sobanska L, De Santi S, Zinkowski R, Mehta P, et al: Prediction and longitudinal study of CSF biomarkers in mild cognitive impairment. Neurobiol Aging 30: 682-690, 2009.

95. Ayton S, Faux NG and Bush AI; Alzheimer's Disease Neuroimaging Initiative: Ferritin levels in the cerebrospinal fluid predict Alzheimer's disease outcomes and are regulated by APOE. Nat Commun 6: 6760, 2015.

96. Ghanbari H, Ghanbari K, Beheshti I, Munzar M, Vasauskas A and Averback P: Biochemical assay for AD7C-NTP in urine as an Alzheimer's disease marker. J Clin Lab Anal 12: 285-288, 1998.

97. Goodman I, Golden G, Flitman S, Xie K, McConville M, Levy S, Zimmerman E, Lebedeva Z, Richter R, Minagar A and Averback P: A multi-center blinded prospective study of urine neural thread protein measurements in patients with suspected Alzheimer's disease. J Am Med Dir Assoc 8: 21-30, 2007.

98. de la Monte SM and Wands JR: The AD7c-ntp neuronal thread protein biomarker for detecting Alzheimer's disease. Front Biosci 7: d989-d996, 2002. 
99. Ma L, Chen J, Wang R, Han Y, Zhang J, Dong W, Zhang X, Wu Y and Zhao Z: The level of Alzheimer-associated neuronal thread protein in urine may be an important biomarker of mild cognitive impairment. J Clin Neurosci 22: 649-652, 2015.

100. Zengi O, Karakas A, Ergun U, Senes M, Inan L and Yucel D: Urinary 8-hydroxy-2'-deoxyguanosine level and plasma paraoxonase 1 activity withAlzheimer's disease. Clin Chem Lab Med 50: 529-534, 2011.

101. Kim KM, Jung BH, Paeng KJ, Kim I and Chung BC: Increased urinary $\mathrm{F}(2)$-isoprostanes levels in the patients with Alzheimer's disease. Brain Res Bull 64: 47-51, 2004.

102. Yoshida M, Higashi K, Kuni K, Mizoi M, Saiki R, Nakamura M, Waragai M, Uemura K, Toida T, Kashiwagi K and Igarashi K: Distinguishing mild cognitive impairment from Alzheimer's disease with acrolein metabolites and creatinine in urine. Clin Chim Acta 441: 115-121, 2015.

103. Rabassa M, Cherubini A, Zamora-Ros R, Urpi-Sarda M, Bandinelli S, Ferrucci L and Andres-Lacueva C: Low levels of a urinary biomarker of dietary polyphenol are associated with substantial cognitive decline over a 3-year period in older adults: The invecchiare in chianti study. J Am Geriatr Soc 63: 938-946, 2015.

104. Cook CN, Murray ME and Petrucelli L: Understanding biomarkers of neurodegeneration: Novel approaches to detecting tau pathology. Nat Med 21: 219-220, 2015.

105. Kfoury N,Holmes BB, Jiang H, Holtzman DM and Diamond MI: Trans-cellular propagation of Tau aggregation by fibrillar species. J Biol Chem 287: 19440-19451, 2012.

106. Holmes BB, Furman JL, Mahan TE, Yamasaki TR, Mirbaha H, Eades WC, Belaygorod L, Cairns NJ, Holtzman DM and Diamond MI: Proteopathic tau seeding predicts tauopathy in vivo. Proc Natl Acad Sci USA 111: E4376-E4385, 2014.
107. Yanamandra K, Kfoury N, Jiang H, Mahan TE, Ma S, Maloney SE, Wozniak DF, Diamond MI and Holtzman DM: Anti-tau antibodies that block tau aggregate seeding in vitro markedly decrease pathology and improve cognition in vivo. Neuron 80: 402-414, 2013.

108. Kong D, Giovanello KS, Wang Y, Lin W, Lee E, Fan Y, Murali Doraiswamy $\mathrm{P}$ and Zhu H: Predicting Alzheimer's disease using combined imaging-whole genome SNP data. J Alzheimers Dis 46: 695-702, 2015.

109. Sun Y, Bresell A, Rantalainen M, Höglund K, Lebouvier T and Salter H; Alzheimer Disease Neuroimaging Initiative: An integrated bioinformatics approach for identifying genetic markers that predict cerebrospinal fluid biomarker $\mathrm{p}$-tau181/A $\beta 1-42$ ratio in ApoE4-negative mild cognitive impairment patients. J Alzheimers Dis 45: 1061-1076, 2015.

110. Castro-Chavira SA, Fernandez T, Nicolini H, Diaz-Cintra S and Prado-Alcala RA: Genetic markers in biological fluids for aging-related major neurocognitive disorder. Curr Alzheimer Res 12: 200-209, 2015

111. Femminella GD, Ferrara $\mathrm{N}$ and Rengo G: The emerging role of microRNAs in Alzheimer's disease. Front Physiol 6: 40, 2015.

112. Namioka N, Hanyu H, Hirose D, Hatanaka H, Sato T and Shimizu S: Oxidative stress and inflammation are associated with physical frailty in patients with Alzheimer's disease. Geriatr Gerontol Int: Jun 14, 2016 (Epub ahead of print).

113. Panza F, Solfrizzi V, Barulli MR, Santamato A, Seripa D, Pilotto A and Logroscino G: Cognitive Frailty: A systematic review of epidemiological and neurobiological evidence of an age-related clinical condition. Rejuvenation Res 18: 389-412, 2015. 